\title{
A TEORIA DA LINGUAGEM DE ÉMILE BENVENISTE: UMA ABERTURA PARA OS ESTUDOS EM AQUISIÇÁO DA LINGUAGEM
}

\section{ÉMILE BENVENISTE'S THEORY OF LANGUAGE: AN OPENING TO LANGUAGE ACQUISITION STUDIES}

\author{
Carmem Luci da Costa Silva \\ Universidade Federal do Rio Grande do Sul, UFRGS, Porto Alegre, RS, Brasil \\ Giovane Fernandes Oliveira \\ Universidade Federal do Rio Grande do Sul, UFRGS, Porto Alegre, RS, Brasil \\ Marlete Sandra Diedrich \\ Universidade de Passo Fundo, UPF, Passo Fundo, RS, Brasil
}

\begin{abstract}
Resumo: Este artigo defende que a teoria da linguagem de Émile Benveniste abre possibilidades para os estudos em aquisiçẫo da linguagem. Para tanto, realiza-se um duplo movimento: retrospectivo, com o retorno às reflexôes benvenistianas sobre a relação da criança com sua língua materna e a escrita dessa língua; prospectivo, com a análise de recortes enunciativos de experiências da criança na linguagem. Em ambos os movimentos, salienta-se a questão do simbolismo da linguagem como fundamento da abstração e princípio da imaginação criadora e, consequentemente, como condição da constituição da criança enquanto falante e escrevente em sua língua materna.
\end{abstract}

Palavras-chave: abstração; aquisição da linguagem; imaginação criadora; simbolismo.

Abstract: This article argues that Émile Benveniste's theory of language opens up for possibilities of language acquisition studies. For this purpose, a double movement is performed: a retrospective one, with a review in the Benvenistian reflections about the relation between the child and his/her mother tongue and the writing of this language; and a prospective one, with the analysis of enunciative clippings of the child's experiences in language. In both movements, language symbolism is highlighted as the basis of abstraction and the principle of creative imagination and, consequently, as a condition for the constitution of the child as a speaker and writer in his/her mother tongue.

Keywords: abstraction; language acquisition; creative imagination; symbolism. 


\section{Introduçáo}

O livro Dernières leçons: Collège de France (1968 et 1969) - originalmente publicado na França em 2012, sob a direção de JeanClaude Coquet e Irène Fenoglio, e, posteriormente, traduzido no Brasil em 2014, com o título Últimas aulas no Collège de France (1968 e 1969) ${ }^{1}$ - incorpora, ao cenário da teorização de Émile Benveniste, o problema da escrita como ligado ao humano na linguagem. Tal fato permite associar essa publicação póstuma aos temas tratados nas obras Problemas de Linguística Geral I e Problemas de Linguística Geral $\mathrm{II}^{2}$, pois, nas Últimas aulas, o tema da relaçáo inicial da criança com a escrita comparece de modo análogo ao tema da relação inicial da criança com a língua materna em alguns capítulos dos PLG. Nesses capítulos, Benveniste aborda justamente a fundação humana na língua, vinculada ao simbolismo da linguagem como fundamento da abstração.

No presente artigo, temos por objetivo mostrar como a ideia benvenistiana de que a criança encontra, na faculdade simbólica da linguagem, a base da abstração viabiliza o desenvolvimento de estudos aquisicionais centrados em realizaçôes vocais/fônicas e gráficas ${ }^{3}$, realizaçôes essas que colocam a criança em relação constante e necessária com a língua. Assim, a discussão que ora iniciamos busca defender que a teoria da linguagem de Benveniste ${ }^{4}$ abre possibilidades a estudos sobre a aquisição da língua materna e de sua escrita.

${ }^{1}$ Doravante, Últimas aulas.

${ }^{2}$ Doravante, PLG I, PLG II e PLG para referência às duas obras.

${ }^{3} \mathrm{O}$ termo realização vocalffônica da língua é utilizado, aqui, com inspiração no texto "O aparelho formal da enunciação", em que Benveniste trata dos aspectos da enunciaçáo: "O mais imediatamente perceptível e o mais direto [...] é a realizaçáo vocal da língua. [...] Na prática científica procura-se eliminar ou atenuar os traços individuais da enunciaçáo fônica [...]. Mas cada um sabe que, para o mesmo sujeito, os mesmos sons não são jamais reproduzidos exatamente" (BENVENISTE, 1989, p. 82, negritos nossos). Já o termo realização gráfica da língua é aqui empregado com inspiração na "Aula 12" das Últimas aulas, na qual Benveniste formula o princípio fundamental da escrita: "No princípio, queremos transmitir ou conservar uma mensagem. Queremos, então, veicular à distância um enunciado, queremos realizar graficamente o semiótico" (BENVENISTE, 2014, p. 156, itálicos do original, negritos nossos).

${ }^{4} \mathrm{~A}$ ideia de uma teoria da linguagem em Benveniste, conforme Flores (2013), está relacionada à consideração, na obra benvenistiana, da proposta enunciativa como uma parte dessa reflexão, talvez uma parte de grande importância, mas não a única, visto haver, em seu trabalho, sempre a preocupação pelos diferentes modos de presença do humano na linguagem. 
Para tanto, inspirados pela proposta deste número temático da Revista Fragmentum, adotamos um duplo viés de leitura da teoria benvenistiana, a um só tempo retrospectivo e prospectivo: retrospectivo, pois revisitamos tanto os PLG quanto as Últimas Aulas, a fim de resgatarmos as reflexóes de Benveniste sobre a relação da criança com sua língua materna e a escrita dessa língua, focalizando, em tais reflexôes, a questão da abstração; prospectivo, pois mobilizamos, neste artigo, recortes enunciativos de experiências da criança na linguagem, a fim de ilustrarmos a abertura que a teoria benvenistiana representa para os estudos aquisicionais.

Esse duplo viés de leitura direciona nossa incursão pelos textos que elegemos como integrantes de nosso corpus teórico: dos PLG I, os artigos Vista d'olhos sobre o desenvolvimento da linguistica e Os niveis da análise linguística; dos PLG II, a entrevista Estruturalismo e linguística; das Últimas aulas, a Aula 8. Além desses textos principais, recorremos a outros que, embora não nucleares em nossa investigação, subsidiam-na em momentos pontuais, caso de Categorias de língua e categorias de pensamento, A forma e o sentido na linguagem, Estrutura da lingua e estrutura da sociedade, $O$ aparelho formal da enunciação, Aula 10, Aula 11 e Aula 12.

Contudo, advertimos o leitor de que não encontrará, nas páginas seguintes, uma teorização acerca de algum fenômeno específico ou mesmo acerca de mudanças na aquisiçáo da língua materna e de sua escrita, abordagem adotada em outros estudos aquisicionais inspirados na reflexão benvenistiana, já publicados ou em andamento 5 . Trata-se, antes, de uma investigação cujo interesse primeiro "é ouvir Benveniste" (COQUET; FENOGLIO, 2014, p. 85, itálico dos autores), mais precisamente ouvir suas formulaçóes sobre a constituição da criança como falante e escrevente em sua língua materna.

Essa escuta conduz a primeira parte deste texto, mais retrospectiva, na qual retomamos a ideia, central nas elaboraçóes benvenistianas sobre a aquisição, da abstração como articulada ao simbolismo linguístico (cf. seção 2). Na segunda parte, mais prospectiva, à voz do mestre, somamos as nossas próprias vozes enquanto estudiosos que, com Benveniste e a partir de Benveniste, buscam produzir o novo em matéria de aquisição da linguagem,

${ }^{5}$ Silva $(2007 ; 2009)$ propôe uma teoria enunciativa em aquisição da linguagem, inspirada em Benveniste (1995; 1989). Ao estudo da autora, seguem-se outros que investigam corpora de enunciaçôes faladas e enunciaçôes escritas/lidas de crianças. Dentre tais estudos relacionados à língua materna em enunciaçôes faladas, citamos o de Stumpf (2010) e o de Diedrich (2015); relacionados a enunciaçóes escritas, há o estudo de Soares (2018) acerca da aquisição da leitura e o estudo em desenvolvimento de Oliveira (no prelo) sobre a aquisiçáo da escrita. 
enfocando a relação da criança com a língua via realizaçôes vocais/fônicas (cf. seção 3) e via realizaçôes gráficas (cf. seção 4).

\section{$2 \mathrm{O}$ simbolismo linguístico e a criança na linguagem}

Pensar a linguagem no humano e o humano na linguagem é pensar o simbolismo que articula essa interdependência homem-linguagem. Ao tratar do poder simbólico da linguagem no humano, Benveniste volta-se para a criança e argumenta que a faculdade simbólica é "inerente à condição humana” (BENVENISTE, 1995, p. 27). É nessa faculdade simbolizante que reside o "fundamento da abstração ao mesmo tempo que o princípio da imaginação criadora” (BENVENISTE, 1995, p. 28).

O linguista salienta que tal capacidade simbólica humana está atrelada ao nascimento das funções conceituais: "Ora, essa capacidade representativa de essência simbólica que está na base das funçôes conceptuais só aparece no homem. Desperta muito cedo na criança [...] na aurora de sua vida consciente" (BENVENISTE, 1995, p. 28). É pelo simbólico, fundamento da abstração, que o autor distingue o homem do animal, pois "náo é possível nos meios de expressão empregados pelos animais um começo ou uma aproximação da linguagem. Entre a função sensório-motora e a função representativa, há um limiar que só a humanidade transpôs" (BENVENISTE, 1995, p. 28). Nessa linha de raciocínio, Benveniste defende que a "ascensão de Homo na série animal pode haver sido favorizada pela sua estrutura corporal ou pela sua organização nervosa; [mas] deve-se antes de tudo à sua faculdade de representação simbólica, fonte comum do pensamento, da linguagem e da sociedade" (BENVENISTE, 1995, p. 29).

Para Benveniste, a faculdade simbólica é a fonte da linguagem e do pensamento, na medida em que a linguagem é a expressão simbólica por excelência e que náo existe pensamento sem linguagem, sendo o próprio conhecimento do mundo determinado linguisticamente. Tal determinação do cognoscível pelo linguístico deve-se ao fato de que "a linguagem reproduz o mundo mas submetendo-o à sua própria organização" enquanto "linguagem articulada [língua], consistindo de um arranjo orgânico de partes, de uma classificação formal dos objetos e dos processos" (BENVENISTE, 1995, p. 26, acréscimo nosso).

Essa classificação formal consiste na configuração da forma do pensamento pela organização articulada da língua, ou seja, a partir da 
decomposição do conteúdo do pensar em categorias linguísticas que fornecem expressão a esse conteúdo. É a língua em sua "função mediadora": "cada locutor não pode propor-se como sujeito sem implicar o outro, o parceiro que, dotado da mesma língua, tem em comum o mesmo repertório de formas, a mesma sintaxe da enunciação e igual maneira de organizar o conteúdo", de modo que, "a partir da função lingüística, e em virtude da polaridade $e u$ : $t u$, indivíduo e sociedade não são mais termos contraditórios, mas complementares" (BENVENISTE, 1995, p. 26, itálicos do autor).

Segundo Benveniste, além da linguagem e do pensamento, a faculdade simbólica é ainda a fonte da sociedade, pois a linguagem é uma entidade mediatizante, por meio da qual o símbolo linguístico realiza-se em uma expressão articulada em determinada língua, própria de uma sociedade particular, emissão essa nunca comum à espécie inteira, mas sempre socialmente situada. Por essa via, o autor sustenta ser a capacidade simbólica a capacidade mais específica do humano e a condição de ele constituir relações com outros e com a própria natureza no estabelecimento da sociedade. A aquisição da língua, com a sociedade dessa língua, é concebida a partir de um duplo axioma: (1) língua e sociedade são dadas; (2) língua e sociedade são aprendidas.

Esse duplo axioma pode receber a formulação interpretativa de que a criança é constituída pela língua, com os valores da sociedade dessa língua, ao mesmo tempo em que a constitui. Tal formulação encontra base nestas instigantes palavras do linguista:

Língua e sociedade não se concebem uma sem a outra. Uma e outra são dadas. Mas também uma e outra são aprendidas pelo ser humano, que não lhes possui um conhecimento inato. A criança nasce e desenvolve-se na sociedade dos homens. São homens adultos, seus pais, que lhe inculcam o uso da palavra. A aquisiçáo da língua é uma experiência que vai a par, na criança, com a formação do símbolo e a construçáo do objeto. Ela descobre as coisas pelo seu nome; descobre que tudo tem um nome e que aprender o nome lhe dá a disposiçẫo das coisas. Mas descobre também que ela mesma tem um nome e que por meio dele se comunica com os que a cercam. Assim desperta nela a consciência do meio social onde está mergulhada e que moldará pouco a pouco o seu espírito por intermédio da linguagem. (BENVENISTE, 1995, p. 31, itálicos do autor, negritos nossos).

A propriedade simbólica da linguagem, atrelada ao poder significante das línguas, é o que possibilita, no manejo humano destas, a produção de 
sentidos, visto que, para uma língua ter existência, precisa estar em uso e significar nas relaçóes entre, pelo menos, dois indivíduos:

Qualquer pessoa pode fabricar uma língua, mas ela náo existe, no sentido o mais literal, desde que não haja dois indivíduos que possam manejá-la como nativos. Uma língua é primeiro um consenso coletivo. Como ele se dá? A criança nasce em uma comunidade linguística, ela aprende a sua língua, processo que parece instintivo, tão natural quanto o crescimento físico dos seres ou dos vegetais, mas o que ela aprende, na verdade, não é o exercício de uma faculdade "natural", é o mundo do homem. A apropriação da linguagem pelo homem é a apropriaçáo da linguagem pelo conjunto de dados que se considera que ela traduz, a apropriação da língua por todas as conquistas intelectuais que o manejo da língua permite. (BENVENISTE, 1989 , p. 20-21, aspas do autor, negritos nossos).

Se o poder simbólico garante que as línguas signifiquem, a existência de uma língua depende que seu manejo produza sentido entre os que a usam. Eis aqui um importante aspecto para a constituição humana na língua: o manejo da língua e um outro para que esse manejo seja constituído como significante. Por isso, Benveniste argumenta em favor da ideia de nascimento da criança na cultura, não na natureza, uma vez que é na relaçáo com outros que o infans apreende "necessariamente com a língua os rudimentos de uma cultura" (BENVENISTE, 1989, p. 23). Essa passagem é complementada pelo linguista da seguinte maneira: "[...] o que a criança adquire, aprendendo, como se diz, a falar, é o mundo no qual ela vive na realidade, que a linguagem lhe dá e sobre o qual ela aprende a agir" (BENVENISTE, 1989, p. 24).

A importância do exercício do discurso - isto é, do manejo da língua - é enfatizada por Benveniste no texto Os níveis da análise linguistica, justamente quando argumenta que "é no discurso atualizado em frases que a língua se forma e se configura” (BENVENISTE, 1995, p. 140). Isso, porque, para o linguista, o reconhecimento de unidades/signos da língua pelo locutor, no início da aquisiçáa, ocorre em sua incessante atividade de linguagem em todas as situaçóes. É por aí que a criança pode reconhecer/ abstrair as formas como constituidoras de sentidos no sistema. Assim, os sentidos discursivos, constituídos nas relaçóes com outros, tornam possível à criança entrar nos sentidos sistêmicos. É, portanto, via ato de enunciação, com a implantaçáo de locutor e alocutário (aspecto da intersubjetividade) e com o estabelecimento da relação discursiva destes com o mundo (aspecto da referência), que a língua, com seus instrumentos formais, passa a ter 
existência. A "inserção do discurso no mundo" (BENVENISTE, 1989, p. 85) é o que dá acesso à língua para a criança e lhe possibilita nascer nas formas e nos sentidos dessa língua-discurso.

Os Problemas de Linguística Geral tematizam a entrada da criança na língua com a consideraçáo, principalmente, do manejo e da mediação dessa língua por intermédio do "aparelho vocal para produzirse e do aparelho auditivo para ser percebida" (BENVENISTE, 1995, p. 30). Por essa relação intersubjetiva é que uma língua pode ser "abstraída" pela criança como um sistema de unidades significativas que viabiliza uma infinidade de manejos singulares. A criança é constituída e constitui-se, pois, nos dois modos de ser língua: língua-sistema e língua-discurso. A reflexão sobre o processo de aquisição centrada nos manejos vocais da língua, com ilustração de recortes enunciativos de crianças, terá lugar na terceira seção; no momento, visitaremos as Últimas aulas para pensarmos a criança em manejos gráficos da língua.

É na Aula 8, a primeira das oito liçôes que integram o capítulo 2 desse livro póstumo ${ }^{6}$, que Benveniste volta-se para a relação criança-escrita, tornando a abordar a questão da abstração. Nessa aula, o linguista parte da asserção de que "vivemos na civilização do livro, do livro lido, do livro escrito, da escrita e da leitura. Nosso pensamento está, em qualquer nível, constantemente informado pela escrita" (BENVENISTE, 2014, p. 127). Essa constante informaçẫo do pensamento pela escrita é definida em termos de uma relaçấo intima da "escrita com a língua toda, a fala e o próprio pensamento" (BENVENISTE, 2014, p. 127). Como entender tal citaçáo? Seriam os termos língua, fala e pensamento itens de uma enumeração? $\mathrm{Ou}$ seria a formulação "a fala e o próprio pensamento" uma glosa explicativa da expressão "língua toda"? Passagens seguintes da Aula 8 autorizam-nos a responder afirmativamente à terceira questão; antes, porém, de chegarmos a

${ }^{6}$ Devido à natureza editorial das Últimas aulas - que, como se sabe, é uma obra estabelecida geneticamente a partir de notas de Benveniste e de alunos que assistiram aos seus derradeiros cursos no Collège de France -, assinalaremos, nas referências entre parênteses, anotaçóes de alunos com a expressáo nota de ouvinte. Isso é possível, porque os editores do livro tiveram o cuidado de distinguir, no corpo do texto, as notas dos ouvintes (em caracteres menores) das notas do professor (em caracteres maiores). Também devido à natureza editorial dessa obra, em citaçôes com destaques, não informaremos "itálicos/aspas do autor", como fazemos em citaçóes dos PLG, mas sim "itálicos/aspas do original"; com tal decisão, não estamos afirmando que esses destaques náo sáo do punho do próprio Benveniste ou de seus ouvintes - estamos apenas resguardando o estatuto de autoria aos PLG enquanto obras que reúnem textos publicados em vida pelo linguista. 
elas, precisamos passar pela definiçấo de escrita elaborada na lição em pauta e pelas abstraçóes que a escrita impóe à criança que a adquire.

Benveniste propóe-se a tratar da língua e da escrita em sua relação primordial. Essa última expressão parece dialogar com a expressão nível fundamental, que, em Estrutura da lingua e estrutura da sociedade, o linguista associa à noção de língua como sistema de formas significantes, condição da comunicação, e à noção de sociedade como coletividade humana, condição da existência dos homens. Com efeito, logo na sequência, o professor enuncia uma definição didática de escrita, que póe em relevo sua natureza sistêmica e abstrata: "a escrita é um sistema que supóe uma abstração de alto grau: abstrai-se do aspecto sonoro - fônico - da linguagem, com toda sua gama de entonação, de expressão, de modulação" (BENVENISTE, 2014, p. 128).

Tal abstração de alto grau estende-se à entrada da criança na escrita ${ }^{7}$, pois "Toda aquisição da escrita supóe uma série de abstraçóes" (BENVENISTE, 2014, p. 30, nota de ouvinte):

1) Uma primeira grande abstração reside, assim, no fato de que a língua se torna uma realidade distinta. De fato, instintivamente, falamos quando temos necessidade ou vontade de falar, em determinadas circunstâncias para obter determinado resultado, com uma pessoa que tem determinada voz, em determinada relação de idade, de amizade etc. Sempre há situaçôes em que o locutor exerce seu falar. [...]

2) A abstração consiste, entáo, em se desprender dessa riqueza contextual, que, para o falante, é essencial.

3) Ele deve falar de coisas fora das circunstâncias que fazem com que tenhamos necessidade de falar delas, enquanto, para ele, são realidades vivas. [...]

4) O processo de aquisição da escrita. (BENVENISTE, 2014, p. 130-131, notas de ouvintes, negritos nossos).

Embora, nas notas dos ouvintes, essas quatro abstrações constem separadas e enumeradas, nas notas de Benveniste, a explicação dada a tais abstraçóes permite reorganizá-las em duas grandes tomadas de consciência da língua pelo locutor na aquisição da escrita.

A primeira tomada de consciência envolve as abstraçóes (1), (2) e (3): “Com a escrita, o locutor deve se desprender da representação que tem

${ }^{7} \mathrm{~A}$ esse respeito, é importante pontuar que Fenoglio (2013) também destaca a presença da noção de abstração na obra Últimas aulas, justamente quando Benveniste observa a aquisição da escrita pela criança. 
instintivamente do falar enquanto atividade, enquanto exteriorização de seus pensamentos, enquanto comunicação viva", devendo "tomar consciência da língua como realidade distinta do uso que dela faz: isso já é uma operação muito trabalhosa - como bem sabem, por experiência, aqueles que ensinam os rudimentos da escrita às crianças" (BENVENISTE, 2014, p. 129). Tratase da conversão da língua em uma imagem da língua, em que todos os fatores contextuais e interlocutivos que alimentam essa manifestação individual e coletiva que é o exercício do falar são substituídos pelo traçado manual de signos. Conforme Benveniste, "a criança deve se abstrair da necessidade que a faz falar, ir brincar com um amigo ou comer uma maçá, para 'objetivar' $\mathrm{o}$ dado linguístico /brincar/ ou /maçã/", sendo arremessada em "uma língua que não se dirige nem a seus amigos nem a seus pais, uma língua da qual não se sabe quem a fala nem quem a ouve" (BENVENISTE, 2014, p. 131, aspas do original).

Por certo, poder-se-ia argumentar que o exercício do escrever também implica os termos que Benveniste associa ao exercício do falar: atividade, exteriorização de pensamentos, comunicação viva. Afinal, ao escrevermos, igualmente estamos em situação de diálogo e somos movidos por uma necessidade de escrever. Como pode, entáo, o linguista caracterizar a escrita enquanto uma língua que figura, para a criança, como destituída de relaçôes com o outro e com o mundo? Ora, o que Benveniste problematiza, aqui, não é a inexistência de intersubjetividade e referência na escrita enquanto comunicação, e sim algo anterior a isso: a suspensão temporária desses fatores em um momento muito inicial da relação da criança com a escrita, no qual ela deve apreender a escrita não como comunicação, mas como objetivação da língua, o que demanda considerar essa no âmbito de uma realidade distinta do uso que dela faz na fala.

Se a apreensão dessa realidade distinta vincula-se à primeira grande tomada de consciência da língua pelo locutor na aquisição da escrita - as abstraçóes (1), (2) e (3) -, a constituição propriamente dita da criança como escrevente atrela-se à segunda grande tomada de consciência - a abstração (4). Trata-se, aqui, não mais da condição da aquisição da escrita (o desprendimento do contexto de fala), mas do seu processo mesmo:

\footnotetext{
${ }^{8}$ Tal objetivação será definida, nas lições seguintes, em termos de autossemiotização da língua, nas quais a noção de escrita como sistema semiótico (semiológico) cede lugar, primeiro, à noção de escrita como instrumento da autossemiotizaçâo da língua e, em seguida, à noção de escrita como forma secundária da fala. Todavia, não é nosso propósito, aqui, problematizar essas diferentes concepçóes de escrita presentes nas Últimas aulas, de maneira que nos restringimos à Aula 8 , que discute mais detidamente a aquisiçấo da escrita pela criança.
} 
"Outro nível de abstração é imposto a quem tem acesso à escrita, a saber: não somente a consciência - ainda que fraca ${ }^{9}$ - do falar transferido à língua, isto é, ao pensamento", como também "a consciência da língua ou do pensamento - na verdade das palavras - representada em imagens materiais. Da palavra ao desenho da palavra realiza-se um salto imenso, do falar à imagem simbólica do falar" (BENVENISTE, 2014, p. 131, itálico do original, negritos nossos). A partir dessa citação, fazemos duas observaçóes.

Primeira observação: as três primeiras expressōes parafrásticas grifadas em negrito no parágrafo anterior - isto é, ou e na verdade - instituem uma equivalência entre língua, pensamento e palavras que autoriza a interpretação que fizemos anteriormente do seguinte trecho que abre a Aula 8: "isso [a constante informação do pensamento pela escrita] relaciona de maneira cada vez mais íntima, extremamente íntima, a escrita com a língua toda, a fala e o próprio pensamento" (BENVENISTE, 2014, p. 127). Em ambas as passagens, os termos língua e pensamento são empregados como sinônimos, porém, enquanto na primeira passagem o terceiro termo a eles alinhado é fala, na segunda passagem, o terceiro termo é palavras. Seriam os termos fala e palavras sinônimos nessas ocorrências? Pensamos que sim e que tal relação sinonímica é corroborada pela própria citação do parágrafo anterior, a qual aproxima os termos palavra e falar, nela também destacados em negrito.

Segunda observação: o salto da palavra/do falar ao desenho da palavra/à imagem simbólica do falar, ao contrário do que o termo salto possa sugerir, não é imediato nem pacífico, pois "a passagem à escrita é uma reviravolta total, muito demorada para se realizar" (BENVENISTE, 2014, p. 130, nota de ouvinte). Tal reviravolta total coloca em cena um outro nível de abstração e simbolização, mais profundo do que o primeiro nível (a primeira tomada de consciência), visto que "o ato de escrever não procede da fala pronunciada, da linguagem em ação, mas da linguagem interior,

${ }^{9}$ Ressalvas de Benveniste como essa do trecho "não somente a consciência - ainda que fraca do falar transferido à língua" (BENVENISTE, 2014, p. 131, negritos nossos), bem como a de trecho anterior - "Eis uma abstração que ele [o locutor, principalmente a criança na aquisição da escrita] deve - ainda que com dificuldade - realizar" (BENVENISTE, 2014, p. 130, negritos nossos) são de extrema importância e nos obrigam a ter cautela no uso da expressão tomada de consciência da língua pelo locutor e de expressôes correlatas. Não se trata de atribuir, ao sujeito da aquisição da escrita, uma intencionalidade psicológica que faria dele um indivíduo plenamente consciente e controlador do seu comportamento linguístico. Como adverte Benveniste (1995, p. 68, negritos nossos), em Categorias de pensamento e categorias de língua, "a realidade da língua permanece, via de regra, inconsciente; excetuado o caso de estudo propriamente lingüístico, não temos senão uma consciência fraca e fugidia das operaçôes que efetuamos para falar" e, acrescentaríamos nós, também das operaçóes que efetuamos para escrever. 
memorizada”. A escrita não é uma representação direta e transparente da fala pronunciada, mas "uma transposição da linguagem interior, e é preciso primeiramente aceder a essa consciência da linguagem interior ou da 'língua' para assimilar o mecanismo da conversão em escrito" (BENVENISTE, 2014, p. 132, aspas do original, negrito nosso). Aqui, a expressão ou ressurge, sobrepondo, dessa vez, os termos linguagem interior e "língua" (com aspas). Seria apenas a reiteraçáo da sinonímia estabelecida anteriormente entre pensamento e língua (sem aspas)? Nesse caso, a linguagem interior estaria para o pensamento como a "língua" estaria para a língua? Cremos que não seja isso por duas razôes: (a) Benveniste (2014, p. 132) mesmo afirma, apesar de não nos conceder maiores explicaçóes, que "transferir essa linguagem interior [...] em uma forma inteligível a outros [...] exige uma atitude inteiramente diferente da que adquirimos por meio do hábito de transferir o pensamento à escrita" - linguagem interior e pensamento, então, não se recobrem; (b) o leitor experiente de Benveniste bem sabe que os recursos tipográficos se revestem de função crítica em seus escritos - "lingua" e língua, portanto, também não se recobrem.

Como se vê, as páginas finais da Aula 8 introduzem uma noção, a de linguagem interior, que opacifica ainda mais a já nebulosa teorização benvenistiana acerca da escrita nas Últimas aulas. Sem condiçôes de nos determos aqui sobre tal noção, gostaríamos apenas de sublinhar que não se pode ignorá-la quando se aventura a estudar o vir a ser escrevente a partir dessa teorização: "Tornar inteligível a linguagem interior é uma operação de conversão que acompanha a elaboração da fala e a aquisição da escrita" (BENVENISTE, 2014, p. 132, nota de ouvinte).

Produto da faculdade humana de simbolizar, que consiste em "representar o real por um 'signo' e de compreender o 'signo' como representante do real, de estabelecer, pois, uma relação de 'significação' entre algo e algo diferente" (BENVENISTE, 1995, p. 27, itálico e aspas do autor), a abstração é uma característica do homem como ser simbólico e racional. De acordo com Benveniste, tais simbolismo e racionalidade permitem ao humano construir representaçóes das coisas e operar sobre elas, classificando a realidade e transformando simbolicamente os elementos da experiência em conceitos distintos dos objetos concretos que representam, em um processo revelador do poder racionalizante do espirito - o termo é do linguista. Esse processo é igualmente revelador do poder estruturante do simbólico - o termo é nosso -, uma vez que é a faculdade simbolizante que está na base da organização da língua em suas realizaçôes vocais/fônicas e gráficas e, pela língua, da organizaçáo da sociedade, do pensamento e da 
realidade. O simbólico é, pois, é o traço mais definidor da humanidade.

\title{
3 A criança em realizaçóes vocais/fônicas da língua
}

Na seção anterior, destacamos que, para Benveniste (1995, 1989), o fundamento da abstração está ligado ao poder simbólico da linguagem e é base das funçóes conceituais no humano. Com efeito, para o linguista, "a faculdade simbólica no homem atinge sua realização suprema na linguagem, que é expressão simbólica por excelência; todos os outros sistemas de comunicações, gráficos, gestuais, visuais, etc. derivam dela e a supóem" (BENVENISTE, 1995, p. 30). Por isso, nesta seção, procuraremos responder à seguinte questão: como, por meio de manejos vocais de formas fônicas, na relação com o outro e com o mundo, a língua materna é "inculcada" na criança ao mesmo tempo em que a criança reconhece e abstrai unidades em sua entrada no sistema de sua língua materna?

Os recortes enunciativos $1^{10}$ e 2 , pertencentes a diferentes corpora de estudo em aquisição de língua materna, podem nos ajudar a responder à questáo desta seção sobre o manejo vocal da língua por crianças em suas atividades discursivas com outros.

\author{
Recorte enunciativo $1^{11}$ \\ Participantes: G (criança investigada), P (pai) e I (investigadora). \\ Idade da $2 ; 0$. \\ criança: \\ Situaçáo: $\quad$ G e seu pai estâo na sala assistindo televisão e \\ brincando com cartas de baralho em atividades de \\ nomeação/identificação dos nomes das gravuras. \\ P: $\quad$ olha cada jipão
}

\footnotetext{
${ }^{10} \mathrm{O}$ corpus de $\mathrm{G}$ pertence ao acervo do grupo de pesquisa interinstitucional NALíngua (Núcleo de Estudos em Aquisição da Linguagem), coordenado pelas Profas. Dras. Alessandra Del Ré (Unesp) e Márcia Romero Lopes (Unifesp).

${ }^{11} \mathrm{Na}$ transcrição, adotamos a seguinte convenção: um cabeçalho informando os participantes da situação de enunciação, indicados por suas iniciais, as quais introduzem também os turnos de diálogo. Os comentários do transcritor sobre aspectos da situação da enunciação são indicados com a expressão "Com". Entre colchetes [ ], são indicadas açốes paralelas à fala, como risos, além de observaçóes sobre o modo de enunciação.
} 


\begin{tabular}{|c|c|}
\hline Com: & a criança vira-se para a TV \\
\hline P: & $\begin{array}{l}\text { olha esse aqui é o caRRÃO [= o pai alonga os } \\
\text { segmentos finais da palavra com pronúncia em tom } \\
\text { ascendente, enfatizando a sonoridade] }\end{array}$ \\
\hline G: & $\begin{array}{l}\text { caRRÃO [= a criança alonga os segmentos finais e } \\
\text { enfatiza a sonoridade da vibrante] }\end{array}$ \\
\hline G: & $\begin{array}{l}\text { caRRÃO [= o pai alonga os segmentos finais da } \\
\text { palavra em tom ascendente com ênfase na sonoridade } \\
\text { da vibrante] }\end{array}$ \\
\hline P: & $\begin{array}{l}\text { caRRÃO [= o pai alonga os segmentos finais da } \\
\text { palavra em tom ascendente com ênfase na sonoridade } \\
\text { da vibrante, evocando a relaçáo da pronúncia desse } \\
\text { segmento com o barulho do carro] }\end{array}$ \\
\hline G: & e ipe \\
\hline P: & jipe de novo, outro jipe \\
\hline G: & oto jipe? \\
\hline P: & e esse aqui? \\
\hline G: & $\begin{array}{l}\text { daDÔ? [= a criança pronuncia com entonaçáo } \\
\text { ascendente de dúvida] }\end{array}$ \\
\hline
\end{tabular}

Nessa brincadeira de nomeação entre a criança e seu pai, vemos o estabelecimento de relaçóes entre nomes e gravuras. No entanto, mais do que esse jogo com a língua, vemos o pai e a criança numa relaçáo humana de integração necessária entre a língua e a cultura, pois o manejo do sufixo "-ão" com entonação ascendente e com ênfase na sonoridade do fonema $/ \mathrm{r} /$ enlaça o sentido das unidades no sistema com um sentido particular de manejo dessas formas nas relaçóes enunciativas de $\mathrm{G}$ com seu pai.

A criança retoma os modos de vocalizaçáo do pai para reproduzir as formas com ênfase na sonoridade da vibrante, na altura e no alongamento do sufixo "-âo". Nessa inversibilidade enunciativa em que comparece no discurso a forma "carrão", atribuem-se sentidos particulares às formas dessa palavra que se instauram na relação $e u-t u$. Aqui, além do sentido intralinguístico das formas enquanto unidades (signos) da língua, ganham saliência, na comunicação intersubjetiva, os sentidos singulares que as formas adquirem pelo modo particular como são enunciadas: é um sentido que enlaça um discurso no outro (o do pai e o da criança) para evocar o barulho do carro, sua beleza e sua potência. Tais valores culturais estão integrados nos modos de enunciar do pai e de G. Para além do que é emitido, a referência do discurso atualiza-se no fato de ambos mobilizarem o vocal 
com determinados caracteres linguísticos que marcam valores particulares ao que nomeiam.

Nesse caso, o manejo do sufixo “-ão", aliado aos elementos vocais da enunciação, atesta valores culturais assumidos pelo pai e partilhados pela criança. É a intersubjetividade constituindo uma história de enunciações da criança por meio de elementos vocais com sentidos que emergem em formas que estáo para além da repetição de fonemas e sufixos. Esses manejos vocais ilustram o modo como fonemas, sufixos e nomes (palavras lexicais) são reconhecidos/abstraídos pela criança, enquanto unidades da língua, via atividades na linguagem em determinadas situaçóes de discurso, e como, nesses exercícios de discurso, a criança nasce nos sentidos culturais inscritos nas formas presentes nas relações de interlocução.

O recorte enunciativo 2 nos ajuda a ilustrar como a criança, no exercício do discurso, em circunstâncias particulares, vivencia uma maneira própria de manejar unidades da mesma língua partilhada com o outro, numa manifestação que é, ao mesmo tempo, individual e coletiva. Este recorte enunciativo faz parte do corpus de pesquisa de Diedrich (2015) e é aqui revisitado para, a partir dele, pensarmos como, por meio de manejos vocais, na relaçáo com o outro e com o mundo, a língua é "inculcada" na criança, ao mesmo tempo em que esta reconhece e abstrai unidades da língua no exercício do discurso.

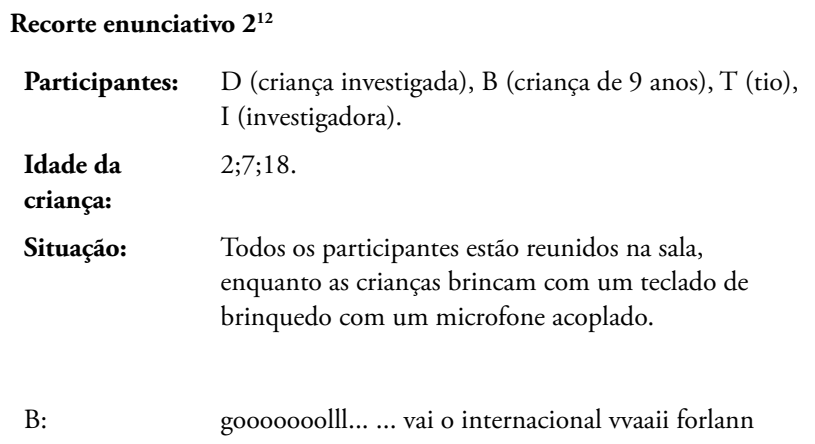

\footnotetext{
${ }^{12}$ Usamos as seguintes normas de transcrição: um cabeçalho contextualiza o dado, as iniciais B, I, D e T identificam as trilhas com enunciados dos participantes, a expressão "com" é usada para identificar a trilha com comentários do transcritor, os alongamentos vocálicos são marcados com a repetição da vogal alongada, as entonaçōes ascendentes são marcadas com letras maiúsculas, o sinal [ indica sobreposição dos enunciados, dentro dos colchetes são indicadas açóes paralelas à fala, como o riso.
} 


\begin{tabular}{|c|c|}
\hline Com: & $\begin{array}{l}\text { B simula narração de futebol ao microfone de } \\
\text { brinquedo do teclado, enquanto ri com as mãos nos } \\
\text { olhos. }\end{array}$ \\
\hline I: & cuiDAdo Ber... LARGA esse microfone \\
\hline Com: & $\begin{array}{l}\text { D tenta tirar o microfone das mãos de } \mathrm{B} \text { e quase } \\
\text { derruba o teclado de brinquedo. }\end{array}$ \\
\hline D: & nnãããuuu \\
\hline Com: & D procura impedir Ber de usar o brinquedo. \\
\hline B: & deixa eu cantá! deixa eu cantá! \\
\hline $\mathrm{T}:$ & desliga agora bê chegachegachega \\
\hline I: & agora chega $[=$ ri $]$ \\
\hline Com: & $\begin{array}{l}\text { D puxa a cadeira de B e segue brincando com outros } \\
\text { objetos sobre uma mesinha próxima. }\end{array}$ \\
\hline B: & $\begin{array}{c}\text { vai internacional vai bater vai fazer o gol GOOOOOL } \\
\text { [ }\end{array}$ \\
\hline D: & eеeеeеeе caаaаaаaаaаaаa \\
\hline Com: & D, cantarolando, mexe nos objetos. \\
\hline B: & é DOO IINTER \\
\hline & {[} \\
\hline D: & ÉUIIII \\
\hline
\end{tabular}

O recorte enunciativo 2 apresenta uma situação enunciativa na qual a criança mais velha, $\mathrm{B}$, de 9 anos, evoca em sua emissão uma experiência anterior: a narraçáo de um jogo de futebol, como mostram os alongamentos vocálicos e os tons ascendentes que revestem as formas lexicais advindas do universo futebolístico. $\mathrm{D}$, uma criança de 2 anos e 7 meses, procura interromper a brincadeira do outro, tirando-lhe o microfone de brinquedo das mãos, uma vez que este parece ser o elemento lúdico que desencadeia a simulação do evento projetado por B naquele momento, evento do qual D não está conseguindo participar. Frente à insistência do outro em continuar construindo o simulacro da narração do futebol, D procura se inserir no projeto enunciativo do outro, embora lhe faltem as formas lexicais completas para tanto.

Essa inserção dá-se pelo manejo de alguns fonemas destacados da fala do outro e revestidos de arranjos vocais que integralizam os fonemas em formas verbais aproximadas às formas usadas pelo outro: "eeeeeee caaaaaaaaaaa". Essas relaçóes intersubjetivas, por meio de procedimentos vocais, garantem à criança ocupar seu lugar enunciativo no simulacro da narração de futebol 
criado por B, o que ocorre, principalmente, via alongamentos vocálicos, assim como em "ÉUIIII". Certamente, não é possível ainda reconhecer uma forma lexical da língua nesses arranjos, mas percebemos a língua sendo "inculcada" na criança, porque, via manejos vocais dos interlocutores, a língua - com suas relações distintivas (significativas) - comparece.

Como heranças humanas, língua e sociedade são instituiçóes dadas e, no exercício do discurso, chegam para a criança. É por manejar a língua com o outro que a criança, imersa em formas e valores sociais, tem tais formas e valores "inculcados" ao mesmo tempo em que ela própria abstrai/reconhece formas com sentidos discursivos e sistêmicos. Nesse manejo, dois aspectos se destacam. Ocupamo-nos deles na sequência.

O primeiro aspecto diz respeito ao fato de a linguagem (a língua), segundo Benveniste (1995, p. 30, aspas do autor), ser um sistema simbólico especial, organizado em dois planos: "de um lado é um fato físico: utiliza a mediação do aparelho vocal para produzir-se, do aparelho auditivo para ser percebida. Sob esse aspecto material presta-se à observação, à descrição e ao registro"; de outro lado, "é uma estrutura imaterial, comunicaçáo de significados, substituindo os acontecimentos ou as experiências pela sua 'evocaçáo"'. O recorte enunciativo 2 ilustra a vivência desses dois planos: no manejo vocal/fônico das formas da língua, B, a criança mais velha, substitui os acontecimentos pela sua evocação no discurso: tanto o jogo de futebol em si quanto a narraçáo do jogo tornam-se acessíveis ao outro por se encontrarem organizados em formas particulares atualizadas em modos de enunciação específicos. É essa experiência que $\mathrm{D}$, a criança mais nova, quer acessar, acesso possível somente por meio de expressóes articuladas de uma determinada língua, o que nos leva ao segundo aspecto.

$\mathrm{O}$ segundo aspecto diz respeito à aprendizagem que o locutor faz do discurso quando aprende a falar, referida por Benveniste em Os niveis da análise linguistica: "O que se torna mais ou menos sensível para ele [o locutor] é a diversidade infinita dos conteúdos transmitidos, em contraste com o pequeno número de elementos empregados" (BENVENISTE, 1995, p. 140). No recorte enunciativo 2, a criança de 2 anos e 7 meses vê-se frente a um novo conteúdo e a uma nova maneira de enunciar: o conteúdo do mundo do futebol, revelado no léxico mobilizado pela criança mais velha; e o modo de enunciar da narração de futebol explicitado nos alongamentos vocálicos e nos tons ascendentes que revestem as formas lexicais usadas. Frente ao novo, é no sistema da língua que a criança busca elementos para organizar seu discurso, manejando, à sua maneira individual, fonemas 
vocálicos num arranjo que busca integralizar formas dadas a fim de que o outro reconheça, em seu enunciar, a mesma língua. Trata-se da vivência, no exercício do discurso, de uma certa familiaridade com o sistema linguístico, a qual só é possível em função do poder simbólico da língua, uma vez que "nada pode ser compreendido que não tenha sido reduzido à língua" (BENVENISTE, 1989, p. 99).

Nesta seção, a análise dos dois recortes enunciativos permite entendermos como a língua materna é "inculcada" na criança por meio de manejos vocais de formas fônicas, o que acontece sempre na relaçáo com o outro e com o mundo. As análises evidenciam flagrantes da criança movendo-se no simbólico da linguagem, pois a criança é constituída por unidades da língua ao mesmo tempo em que as constitui em relaçóes intersubjetivas e referenciais. A criança, assim, fundamenta-se como sujeito na linguagem em movimentos singulares de apreensão da língua em seus dois modos de existir: como sistema e como discurso. Concebemos, com Benveniste (1995), que é nos discursos atualizados em frases que as unidades linguísticas formam-se e configuram-se. Portanto, é nas relações discursivas com outros que a criança pode nascer em sua língua materna, a qual está impregnada dos valores da cultura de sua sociedade.

\section{A criança em realizaçóes gráficas da língua}

Não menos do que na relação inicial da criança com a língua em realizações vocais/fônicas, sua relação inicial com a língua em realizações gráficas é também fundada no simbolismo da linguagem. A julgar pela reflexão de Benveniste na Aula 8 , consideramos não ser precipitado declarar que, na aquisição da escrita, a aptidão humana à abstração é impulsionada a patamares ainda mais elevados. Vejamos um episódio dessa renovada relação com a faculdade simbólica que é desencadeada pela inscrição da criança na escrita $^{13}$.

\footnotetext{
${ }^{13}$ Em um estudo de aquisiçấo da escrita à luz da teoria da linguagem benvenistiana, a noção de recorte enunciativo, que constitui a unidade de análise em estudos aquisicionais filiados a essa perspectiva teórica (SILVA, 2009; DIEDRICH, 2015), precisa ser redimensionada. Afinal, não se trata mais, como em estudos de aquisição da língua em sua realização vocal/fônica, somente de um recorte da alocuçấo falada entre a criança e o outro: é preciso também dar conta do enunciado escrito nessa alocuçáo. Por isso, o recorte enunciativo seguinte é uma unidade de análise desdobrada em dois planos enunciativos: (a) um plano situacional, ligado à situaçáo de enunciaçáo em que a criança, na relação com o outro da alocução falada e com o outro do enunciado escrito (intersubjetividade), produz escrita e leitura sobre um assunto
} 


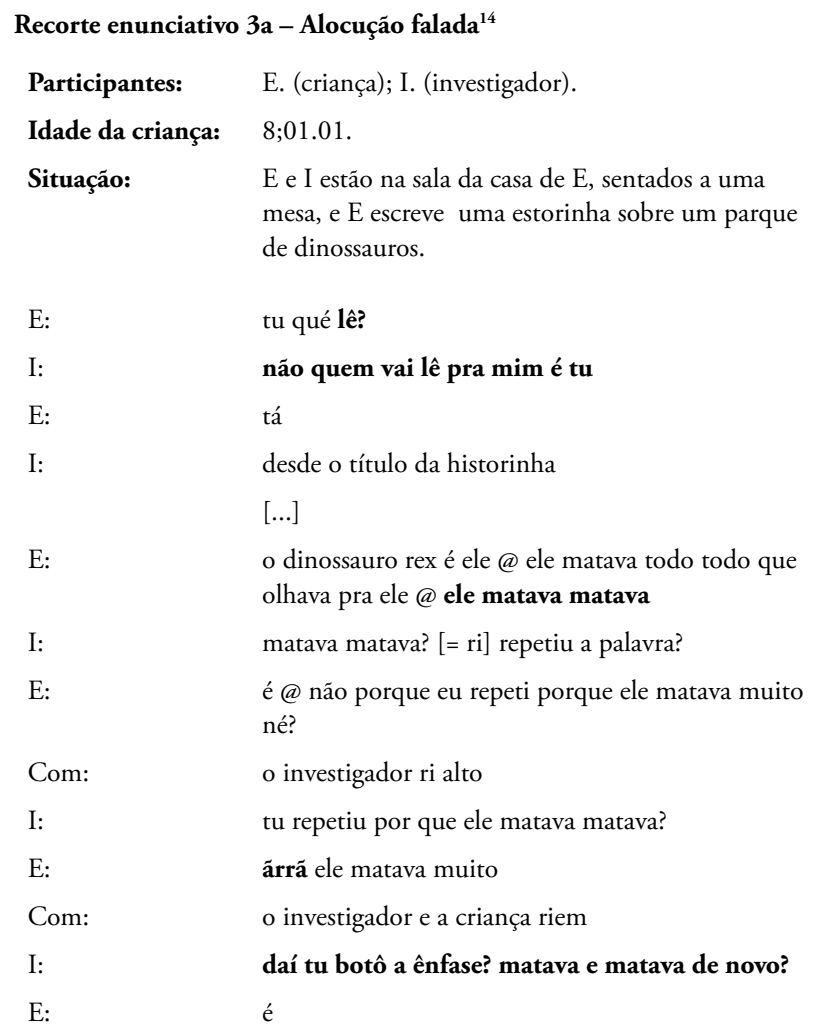

específico (referência); (b) um plano discursivo, relativo ao discurso escrito pela criança no plano situacional. Nessa direção, o plano situacional envolve uma esfera "contextual" de análise (o aqui-agora da alocução falada), enquanto o plano discursivo envolve uma esfera "textual" de análise (o enunciado escrito pela criança nessa alocução). Contemplam-se, dessa maneira, tanto $o$ ato de enunciação - o processo intersubjetivo e referencial - quanto o discurso enunciado - o produto material de forma e sentido resultante desse processo (OLIVEIRA, no prelo).

${ }^{14} \mathrm{Na}$ transcriçáo deste recorte 3 , oriundo do corpus da pesquisa em andamento de Oliveira (no prelo), são adotadas as mesmas convençóes do recorte 1, com o acréscimo das seguintes marcas: “@” para indicar pausa curta e negrito para destacar trechos analiticamente relevantes. 


\section{Recorte enunciativo $3 b$ - Enunciado escrito}

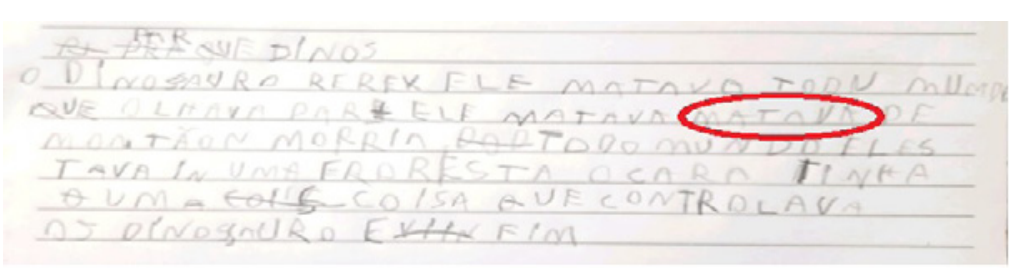

No recorte enunciativo 3a (da alocuçáo falada), a criança (E) é inicialmente convocada pelo outro (I) a deslocar-se do lugar enunciativo de escrevente, preenchido ao escrever a estorinha que constitui o recorte enunciativo $3 \mathrm{~b}$ (do enunciado escrito), para o lugar enunciativo de leitor, que preenche ao atender a convocação do alocutário e ler em voz alta a estória recém-escrita. Tanto na produção escrita quanto na leitura, há manejos gráficos ainda não inteiramente de acordo com a escrita constituída, como a reduplicação silábica em "rerex". Porém, uma das características que mais chama a atenção, no enunciado escrito, é a completa ausência de sinais de pontuação na contenção do fluxo gráfico.

Ao fim da Aula 11, Benveniste (2014, p. 152) observa que "a fala primária é um fluxo de palavras, um contínuo. A fala secundária (a escrita) também é, em muitos casos, um contínuo [...]. Ela também pode ser afetada por separações", sendo "a pontuação [...] a expressão em linguagem secundária das divisóes e entonaçóes sintáticas da linguagem primária”. O que o recorte 3 bá a ver é um escrevente ainda não sensível aos sinais de pontuação como procedimentos acessórios (BENVENISTE, 1989) da enunciação escrita, vale dizer, como instrumentos linguísticos que organizam a totalidade do escrito e os segmentos que integram tal totalidade. Essa não apreensão da função organizacional da pontuação parece sinalizar que a segunda tomada de consciência da língua pelo locutor na aquisiçâo da escrita (a quarta abstraçáo, vinculada à percepção das palavras representadas em imagens materiais e à produção dessas materialidades imagéticas na transposição da linguagem interior em uma forma inteligível) ainda é, para ele, um desafio.

Entretanto, um obstáculo que parece ter já sido superado pelo escrevente é a primeira grande tomada de consciência (as três abstraçóes iniciais, atreladas ao desprendimento do contexto de fala e de todos as variáveis situacionais que o enriquecem). Isso porque $\mathrm{E}$ já demonstra não só um distanciamento da situação de diálogo em que a língua é realizada vocalmente/fonicamente, como também a projeção de uma nova situação 
enunciativa, a qual vai sendo desenhada no ato mesmo em que o linguístico é realizado graficamente e que assume sua configuração final no produto desse ato, o enunciado escrito. Que nova situação é essa? A da narrativa escrita. E é bem um recurso narrativo que emerge como principal procedimento acessório da enunciaçáo escrita nos recortes $3 \mathrm{a}$ e $3 \mathrm{~b}$ : trata-se da repetição "matava matava". Diante dessa repetiçáo, o outro, que acompanha a leitura em voz alta pela criança, interroga-lhe: "matava matava? [= ri] repetiu a palavra?", ao que o menino lhe responde: "é @ náo porque eu repeti porque ele matava muito né?".

Se essa foi ou náo uma intençáo prévia da criança no planejamento de seu enunciado escrito, estamos impossibilitados de saber, pois não temos acesso ao que ela quis dizer, só ao que efetivamente disse, só ao seu querer dizer enquanto pensamento já atualizado linguisticamente (BENVENISTE, 1989). Esse pensamento já atualizado em discurso gráfico é, a partir da interpelação do alocutário, interpretado (significado) pela criança via discurso falado, em um movimento de retorno sobre o signo linguístico em que ela se mostra "capaz de interpretá-lo na sua função significativa e não mais, apenas, de percebê-lo como impressão sensorial" (BENVENISTE, 1995, p. 29), impressão sensorial essa que poderia justificar a repetição da forma verbal somente como um descuido de visão, a exemplo da reduplicação silábica em "rerex". A repetição da unidade, então, irrompe no agenciamento sintagmático enquanto recurso expressivo de constituição do narrado, dando testemunho do "poder fundador da linguagem, que instaura uma realidade imaginária”, tornada possível pelo simbólico como "fundamento da abstraçáo ao mesmo tempo que o princípio da imaginação criadora” (BENVENISTE, 1995, p. 27-28). Nesses deslocamentos entre os lugares enunciativos de falante e escrevente, a criança dá mostras de ser já sujeito na escrita de sua língua materna.

\section{Conclusáo}

Este artigo partiu do pressuposto de que o tema da aquisição da linguagem nos autoriza a executar dois movimentos: passar da tematização desse fenômeno em Benveniste (movimento retrospectivo) para estudos aquisicionais que consideram os manejos vocais e gráficos numa relação constante e necessária da criança com a língua em situaçôes de interlocução (movimento prospectivo). Destacamos o fato de que, nos PLG I e II, encontramos a tematização da aquisição da língua materna no alvorecer 
da vida humana e, nas Últimas aulas, encontramos a tematização da aquisição da escrita. Com base nessas tematizaçóes desenvolvidas pelo autor, as quais se vinculam ao simbolismo da linguagem como fundamento da abstração e princípio da imaginação criadora, bem como na análise de recortes enunciativos de experiências de crianças na linguagem, chegamos às seguintes constataçôes:

(1) Na aquisição da língua em sua realização vocal/fônica, a criança, em relações com o outro e com o mundo, vivencia o simbólico da linguagem, o que lhe permite fazer abstraçóes, via manejos vocais das formas fônicas, acerca da configuração do sistema linguístico a partir do reconhecimento do signo sob a espécie da palavra, unidade da língua-discurso que carrega os valores partilhados tanto sistêmica quanto socialmente pela comunidade em que a criança nasce e cresce. É a constituição da criança como falante no simbólico da língua e da cultura, como preconiza Benveniste nos PLG.

(2) $\mathrm{Na}$ aquisição da língua em sua realização gráfica, a criança, também em relaçóes intersubjetivas e referenciais, enfrenta duas grandes abstrações, uma ligada ao desprendimento do contexto da fala e outra atrelada à imersão no contexto de escrita, a qual se dá via manejos gráficos. Esses manejos possibilitam movimentos como a constituição da narrativa escrita por meio de recursos expressivos que testemunham o poder fundador da linguagem na instauraçáo de realidades imaginárias. Trata-se, aqui, da constituição da criança como escrevente e da renovação de sua relação com o simbolismo linguístico e cultural, ao apreender os rudimentos do escrito e, por intermédio destes, os rudimentos da civilização do livro, da escrita e da leitura, conforme postula Benveniste nas Últimas aulas.

Evidenciamos, assim, que a obra benvenistiana não somente possibilita a teorização sobre o fenômeno da aquisição da língua materna e de sua escrita, como também fornece princípios à análise dos fatos de linguagem que marcam a trajetória da criança na sua experiência de aquisição. Nesse sentido, acreditamos que a abordagem proposta neste artigo viabiliza um retorno renovado à teoria da linguagem de Émile Benveniste a partir de movimentos teóricos e analíticos sobre a aquisição da linguagem, sustentados por leituras retrospectivas e prospectivas da obra do linguista.

\section{Referências}

BENVENISTE, Émile. Problemas de Linguística Geral II. Campinas, SP: 
Pontes Editores, 1989. Original publicado em 1974.

Problemas de Linguística Geral I. Campinas, SP: Pontes Editores, 1995. Original publicado em 1966.

. Últimas aulas no Collège de France (1968 e 1969). 1.ed. São

Paulo: Editora Unesp, 2014. Organização de Jean-Claude Coquet e Irène Fenoglio. Original publicado em 2012.

DIEDRICH, Marlete Sandra. Aquisiçáo da linguagem: o aspecto vocal da enunciação na experiência da criança na linguagem. Tese (Doutorado em Estudos da Linguagem). Programa de Pós-Graduação em Letras, Universidade Federal do Rio Grande do Sul, Porto Alegre, 2015.

FENOGLIO, Irène. Les Dernières leçons d'Émile Benveniste au Collège de France. Nouveau regard sur l'écriture. Letras, Santa Maria. v. 23, n. 46, p. 67-81, jan./jun., 2013.

FLORES, Valdir do Nascimento. Introduçáo à teoria enunciativa de Benveniste. São Paulo: Parábola, 2013.

OLIVEIRA, Giovane Fernandes. A relação teoria-empiria e o problema do dado na pesquisa em aquisição da escrita: um olhar enunciativo. In: ; ARESI, Fábio. $\mathbf{O}$ universo benvenistiano: enunciação, sociedade, semiologia. São Paulo: Pimenta Cultural, 2020, no prelo.

SILVA, Carmem Luci da Costa. A instauraçáo da criança na linguagem: princípios para uma teoria enunciativa em aquisição da linguagem. Tese (Doutorado Estudos da Linguagem). Programa de Pós-Graduaçáo em Letras, Universidade Federal do Rio Grande do Sul, Porto Alegre, 2007.

A criança na linguagem: enunciação e aquisiçăo. Campinas: Pontes Editores, 2009.

SOARES, Isadora Laguna. No mundo de sof: um estudo sobre a aquisição da leitura pela criança a partir da teoria da linguagem de Émile Benveniste. Dissertação (Mestrado em Estudos da Linguagem). Programa de PósGraduação em Letras, Universidade Federal do Rio Grande do Sul, Porto Alegre, 2018.

STUMPF, Elisa Marchioro. Uma proposta enunciativa para o tratamento da metalinguagem na aquisiçáa da linguagem. Dissertação (Mestrado em Estudos da Linguagem). Programa de Pós-Graduação em Letras, Universidade Federal do Rio Grande do Sul, Porto Alegre, 2010. 